\title{
Changes in Mineral Blood Exchange in Orthopedically Sick Cows When Using Complex Treatment
}

\author{
Eugene Marin*1, Valery Ermolaev ${ }^{1}$, Oksana Marina ${ }^{1}$ and Igor Nenashev $^{2}$ \\ ${ }^{1}$ Ulyanovsk State Agrarian University named after P.A. Stolypin, Ulyanovsk, Russia \\ ${ }^{2}$ Samara State Agrarian University, Samara, Russia
}

\begin{abstract}
This article presents the results of a study of mineral components of the blood of cows suffering from purulent-necrotic ulcers in the area of the sheep during their complex treatment. In orthopedically ill animals, an imbalance in the mineral metabolism system was detected, namely, a tendency to decrease the content of calcium, phosphorus, sodium and magnesium, as well as a tendency to increase the content of potassium. As a result of the undertaken therapy of purulent pododermatitis, the dynamics of the studied indicators in the experimental groups was more pronounced and positive, which may indicate the effectiveness of the measures taken.
\end{abstract}

\section{Introduction}

Animal diseases, among which purulent tissue lesions, in particular limbs and hooves, occupy one of the first places, turn into an acute problem in cattle farms. These diseases affect a large number of animals, which is most often observed in cattle. Diseases in the area of fingers in cows cause huge economic damage to farms due to the high frequency of manifestation and wide prevalence both in our country and abroad.

The unstoppable and prolonged use of antibiotics in "any" circumstances to sick animals over time contributed to the development of antibiotic resistance of microorganisms, which significantly reduced their therapeutic effectiveness. Against this background, it is now necessary to study alternative ways of intensifying production in order to obtain the maximum yield of safe and high-quality livestock products. However, we cannot assume that all the issues of this complex problem have been solved [1,2].

It should be noted that some authors focus on the infectious beginning of this pathology, others-on the conditions of maintenance, feeding, injuries in the conditions of intensification of dairy production, the surrounding pathogenic microflora, the absence of planned orthopedic cleaning of hooves, exercise and not performing veterinary and sanitary measures [3-5].

In our opinion, this issue should be considered comprehensively, paying attention to each etiological aspect of the problem under study, individually approaching each specific animal, taking into account the productivity, appearance, state of metabolism, genetic predisposition, creating proper full-fledged feeding, comfortable conditions for the vital activity of the whole organism. Only the planned, systematic, daily work of veterinary specialists, animal technicians, breeders, service personnel can lead to the successful elimination of diseases in the hoof area in cows.

The main indicator that reveals the picture of metabolism in the body of animals is blood. As one of the most important systems of the body, it plays an important role in its vital activity. At the same time, the correct choice of indicators that best reflect all aspects of the metabolism and the state of health of the animal is of particular importance.

During laboratory blood tests, indicators indicating changes occurring in the body are determined, which is especially important when detecting deviations in the initial stages of diseases, when there are no clinical manifestations yet [6].

At the moment, quite a lot of various methods of treating purulent-necrotic processes in the distal limb region have been developed and introduced into clinical practice, but, despite these circumstances, none of them is highly effective [7-9].

The progress of treatment of this pathology depends to a greater extent on local treatment. In this regard, it remains expedient to search for such methods and means of treatment that have a versatile effect that provides persistent antimicrobial, anti-inflammatory and regenerative effects. In this regard, the possibilities of therapeutic use of sorption preparations as synthetic biologically active sorbents for purulent-necrotic processes of the distal extremities in animals are of great interest [10].

The purpose of this work was to study the dynamics of indicators of mineral blood metabolism in cows with purulent-necrotic ulcers in the hoof area against the background of complex sorption therapy.

* Corresponding author: evgenimari@yandex.ru 


\section{Results and Discussion}

Experimental studies were carried out on the basis of LLC PSK "Krasnaya Zvezda" of the Ulyanovsk district of the Ulyanovsk region. From among the examined animals of the black-and-white breed aged from 4 to 10 years, with a live weight of $500 \ldots 550 \mathrm{~kg}, 15$ were selected with diseases of the distal extremities, with a diagnosis of purulent-necrotic ulcer of the distal extremities (Figure 1).

Three experimental groups of ten animals each were formed, two of them experimental and one control. The conditions of maintenance, feeding and care were the same.

In the control group, in the hydration phase, oxytetracyclin was applied topically in the form of powder, in the dehydration phase, $3 \%$ tetracycline ointment was used.

The animals of the first experimental group, in the hydration phase, were locally used diotevin powder (with the antiseptic dioxidin and the proteolytic enzyme terrilitin), 5\% dioxidin ointment was used in the dehydration phase. In the second experimental group, in the hydration phase, diovine powder (with the antiseptic dioxidine) was applied topically to the wound defect, $5 \%$ dioxidine ointment was used in the dehydration phase. The preparations Diovin (Aseptisorb D) and Diotevin (ASEPTISORB DT) are biologically active draining sorbents produced by LLC M. K. Aseptika, Moscow.

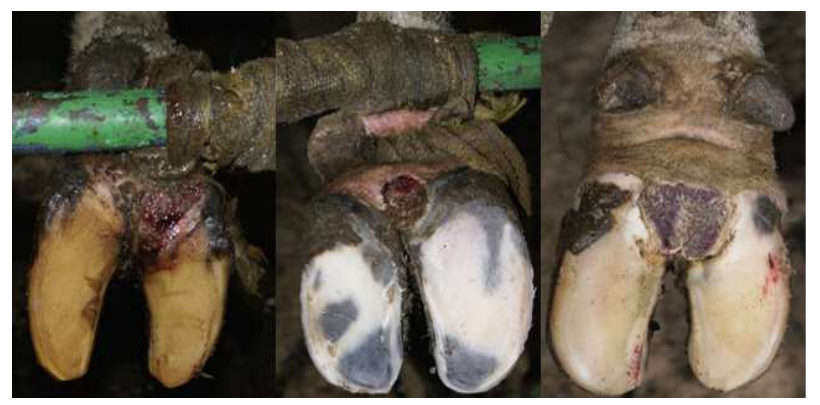

Figure 1. Purulent-necrotic ulcers in the distal region

Biochemical studies were performed before the start of treatment, on the 7th, 14th, 21st and 28th days. Mineral elements were determined in plasma, which was prepared by centrifugation of stabilized blood of experimental animals, using an automatic biochemical analyzer Biochem SA.

The resulting digital material was subjected to statistical processing on the computer program "Statistika 6".

During the entire study period, the calcium content in all the test animals changed statistically significantly $(\mathrm{P}<0.01 \ldots \mathrm{P}<0.001)$. It was established that before the start of treatment, the amount of calcium in the blood of experimental cows was $1.36 \pm 0.12 \ldots 1.53 \pm 0.12 \mathrm{mmol} / \mathrm{l}$. In the control group, the calcium content, starting from day 7 , was higher than the initial data by $0.56 \mathrm{mmol} / \mathrm{l}$ or $36.60 \%$ at $(\mathrm{P}<0.01)$, reliable values of this indicator were stored until day 28 (table 1), reaching their maximum by $0.93 \mathrm{mmol} / \mathrm{l}$ or $60.78 \%$ with $(\mathrm{P}<0.001)$.
A similar pattern was established in both experimental groups, the maximum values were set on the 28th day, respectively in the first experimental group by $1.09 \mathrm{mmol} / \mathrm{l}$ or $78.99 \%$ with $(\mathrm{P}<0.001)$ and in the second experimental group - by $1.36 \mathrm{mmol} / \mathrm{l}$ or 2 times with $(\mathrm{P}<0.001)$.

Table 1. Dynamics of indicators of mineral metabolism of cows with purulent-necrotic ulcers in the hoof area

\begin{tabular}{|c|c|c|c|c|}
\hline 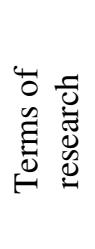 & $\stackrel{0}{0}$ & 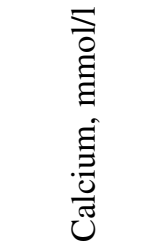 & 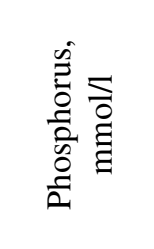 & 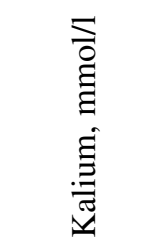 \\
\hline \multirow{3}{*}{ 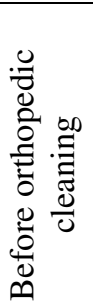 } & $\mathrm{K}$ & $1.53 \pm 0.12$ & $1.20 \pm 0.06$ & $4.84 \pm 0.34$ \\
\hline & $1-\mathrm{O}$ & $1.38 \pm 0.07$ & $1.21 \pm 0.19$ & $4.70 \pm 0.30$ \\
\hline & $2-\mathrm{O}$ & $1.36 \pm 0.12$ & $1.14 \pm 0.10$ & $4.77 \pm 0.35$ \\
\hline \multirow{3}{*}{ 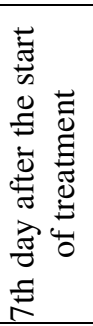 } & $\mathrm{K}$ & $\begin{array}{c}2.09 \pm 0.12 \\
* *\end{array}$ & $\begin{array}{c}1.57 \pm 0.09 \\
* *\end{array}$ & $\begin{array}{c}3.93 \pm 0.20 \\
*\end{array}$ \\
\hline & $1-\mathrm{O}$ & $\begin{array}{c}2.50 \pm 0.17 \\
* * *\end{array}$ & $1.26 \pm 0.14$ & $\begin{array}{c}3.87 \pm 0.26 \\
*\end{array}$ \\
\hline & $2-\mathrm{O}$ & $\begin{array}{c}2.07 \pm 0.11 \\
* * *\end{array}$ & $\begin{array}{c}1.53 \pm 0.09 \\
*\end{array}$ & $4.05 \pm 0.22$ \\
\hline \multirow{3}{*}{ 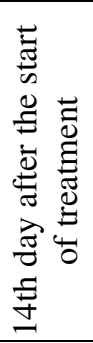 } & $\mathrm{K}$ & $\begin{array}{c}2.29 \pm 0.11 \\
* * *\end{array}$ & $\begin{array}{c}1.72 \pm 0.09 \\
* * *\end{array}$ & $\begin{array}{c}3.65 \pm 0.20 \\
* *\end{array}$ \\
\hline & $1-\mathrm{O}$ & $\begin{array}{c}2.22 \pm 0.06 \\
* * *\end{array}$ & $1.53 \pm 0.20$ & $3.82 \pm 0.42$ \\
\hline & $2-\mathrm{O}$ & $\begin{array}{c}2.14 \pm 0.07 \\
* * *\end{array}$ & $1.29 \pm 0.14$ & $4.03 \pm 0.32$ \\
\hline \multirow{3}{*}{ 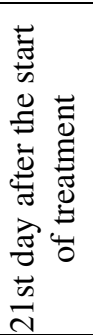 } & K & $\begin{array}{c}2.25 \pm 0.09 \\
* * *\end{array}$ & $1.30 \pm 0.16$ & $\begin{array}{c}3.06 \pm 0.20 \\
* * *\end{array}$ \\
\hline & $1-\mathrm{O}$ & $\begin{array}{c}2.49 \pm 0.13 \\
* * *\end{array}$ & $1.54 \pm 0.15$ & $\begin{array}{c}3.10 \pm 0.16 \\
* * *\end{array}$ \\
\hline & $2-\mathrm{O}$ & $\begin{array}{c}2.32 \pm 0.09 \\
* * *\end{array}$ & $\begin{array}{c}1.60 \pm 0.19 \\
*\end{array}$ & $\begin{array}{c}3.44 \pm 0.19 \\
* *\end{array}$ \\
\hline \multirow{3}{*}{ 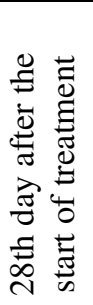 } & K & $\begin{array}{c}2.46 \pm 0.06 \\
* * *\end{array}$ & $\begin{array}{c}1.94 \pm 0.12 \\
* * *\end{array}$ & $\begin{array}{c}2.59 \pm 0.08 \\
* * *\end{array}$ \\
\hline & $1-\mathrm{O}$ & $\begin{array}{c}2.47 \pm 0.09 \\
* * *\end{array}$ & $\begin{array}{c}1.92 \pm 0.09 \\
* *\end{array}$ & $\begin{array}{c}3.01 \pm 0.61 \\
*\end{array}$ \\
\hline & $2-\mathrm{O}$ & $\begin{array}{c}2.72 \pm 0.09 \\
* * *\end{array}$ & $\begin{array}{c}2.26 \pm 0.12 \\
* * *\end{array}$ & $\begin{array}{c}2.30 \pm 0.08 \\
* * *\end{array}$ \\
\hline
\end{tabular}

relative to the data obtained before orthopedic clearance. 
The phosphorus concentration on the first day of treatment was in the range of $1.14 \pm 0.10 \ldots 1.21 \pm 0.19$ $\mathrm{mmol} / \mathrm{l}$ with a subsequent increase in all experimental groups. In the control group, a significant increase in this indicator was noted on the 7th day - by $30.83 \%$ with $(\mathrm{P}<0.01)$, on the 14 th day - by $43.33 \%$ with $(\mathrm{P}<0.001)$ and on the 28 th day - by $61.67 \%$ with $(\mathrm{P}<0.001)$. In the first experimental group, the phosphorus level increased unreliably until the 21 st day. On the $28^{\text {th }}$ it increases significantly to its maximum, on average by $58.78 \%$ with $(\mathrm{P}<0.01)$. In the second experimental group, significant changes were noted on the 7 th day - by $34.21 \%$ with $(\mathrm{P}<0.05)$, on the 21 st day - by $40.35 \%$ with $(\mathrm{P}<0.05)$ and on the 28th day - by $98.25 \%$ with $(\mathrm{P}<0.001)$.

The kalium level before the start of treatment in the control group was $4.84 \pm 0.34 \mathrm{mmol} / \mathrm{l}$, starting from the 7 th day of treatment. A decrease of $18.80 \%$ was noted with $(\mathrm{P}<0.05)$, the reliable dynamics of the decrease in the analyzed indicator remained until the 28th day, approaching its minimum - up to $2.59 \pm 0.08 \mathrm{mmol} / 1$ or $46.49 \%$ with $(\mathrm{P}<0.001)$. In the first experimental group, on the 7 th day, the kalium concentration significantly decreased by $17.66 \%$ at $(\mathrm{P}<0.05)$, on the $21^{\text {st }}-$ by $34.04 \%$ with $(\mathrm{P}<0.001)$ and on the 28 th day - by $35.96 \%$ with $(\mathrm{P}<0.001)$. In the second experimental group, the kalium content in the blood of experimental animals tended to decrease, so by the 14th day the decrease was $15.51 \%$. Then there were significant changes, so on the $21^{\text {st }}-27.88 \%(\mathrm{P}<0.01)$ and on the 28 th day $-51.78 \%$ $(\mathrm{P}<0.001)$.

The sodium content in the blood of sick cows at the beginning of treatment ranged from $135.39 \pm 5.45 \ldots 140.04 \pm 8.18 \mathrm{mmol} / \mathrm{l}$. Later there was an insignificant increase in this indicator at all stages of the study. So, in the control group, the sodium level changed from $0.15 \%$ to $8.56 \%$. In the first experimental group on the 7 th day it slightly decreased by $0.73 \%$, and then increased from $0.72 \%$ to $7.11 \%$. In the second experimental group, it increased from $3.28 \%$ to $6.00 \%$ (table 2).

The level of magnesium in the blood of experimental animals ranged from $0.77 \pm 0.12 \ldots .0 .91 \pm 0.09 \mathrm{mmol} / \mathrm{l}$, during the treatment of sick cows with purulent-necrotic ulcers in the hoof area, a uniform increase occurred. In the control group, the magnesium content increased significantly up to 21 days, the excess was $12.09 \%$. By the 28th day there was a significant increase of $41.76 \%$ with $(\mathrm{P}<0.01)$. In the first experimental group, similar changes were noted: on the 21 st day $-33.77 \%$ and on the 28th day $-62.34 \%$ with $(\mathrm{P}<0.01)$. In the second experimental group, unreliable changes were observed up to 14 days, the excess was $10.23 \%$, and on the 21 st and 28th days, the magnesium level was statistically significant, respectively by $23.86 \%$ with $(\mathrm{P}<0.05)$ and $31.82 \%$ with $(\mathrm{P}<0.01)$.

Summarizing the data obtained, it should be noted that the level of $\mathrm{Ca}$ in the blood is determined by its intake with food, absorption in the gastrointestinal tract, reabsorption in the kidneys, and so on. An increase in the content of $\mathrm{Ca}$ in the blood serum is primarily associated with the process of its release from bone tissue, under ultraviolet irradiation, synthesized from the subcutaneous layer, which is regulated by parathyroid hormone, active vitamin D metabolites (especially calcitriol) and calcitonin [11].

Table 2. Dynamics of indicators of mineral metabolism of cows with purulent-necrotic ulcers in the hoof area

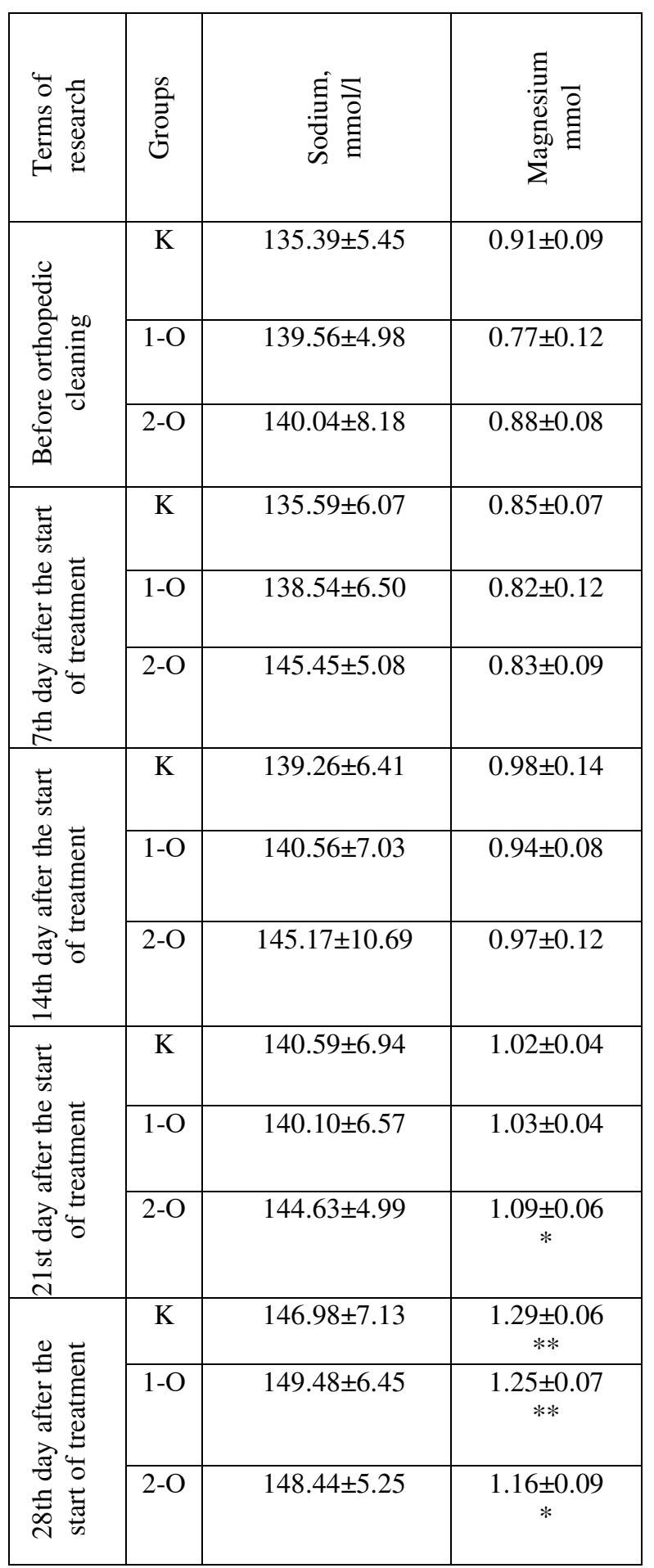

Note: * $(\mathrm{P}<0.05) ; * *(\mathrm{P}<0.01) ; * * *(\mathrm{P}<0.001)$ relative to the data obtained before orthopedic clearance.

In all cows, a violation of the ratio of calcium and phosphorus was detected to one degree or another. At the same time, in cows with purulent-necrotic lesions, the 
calcium content in all cases was lower than normal. It is known that a lack of calcium in the body or a violation of the phosphorus-calcium ratio negatively affects the state of natural resistance of the cows ' body. In addition, calcium ions have a regulating effect on the acid-base balance and the central nervous system [12].

Calcium is a part of the body's buffer systems and participates in maintaining the acid-base balance in the body, so one of the reasons for low calcium levels is considered to be an increased consumption for neutralizing acidic metabolic products and reducing acidosis.

Another reason for hypocalcemia may be insufficient provision of the animals' needs for calcium, since a large amount of it is spent on the formation of milk. The low level of inorganic phosphorus in the blood of animals is due to its lack in feed; this is also facilitated by low absorption of phosphorus in the intestines and a deficiency of vitamin D. The low level of inorganic phosphorus in the blood may be due to its insufficient absorption from the intestines with a lack of iodine in the diet [13].

The marked increase in the potassium content in the blood leads to a violation of the normal ratio of electrolytes (sodium, potassium and calcium). The change in the calcium/potassium ratio affects the state of the tone of the nervous system and causes increased hyperemia.

At the same time, there is a certain parallelism between the increase in the content of potassium ions and the intensity of the purulent-inflammatory process. $\mathrm{Mg}$ deficiency increases the sensitivity of the body to infection with a more pronounced bacterial-toxic shock, while microorganisms more actively produce betalactamase, which determines resistance to penicillin antibiotics.

Therefore, a decrease in the level of $\mathrm{Mg}$ in the blood serum is regarded as one of the reasons predisposing to the development of inflammatory diseases [14].

\section{Conclusion}

Thus, when studying the mineral metabolism of blood in purulent-necrotic ulcerative lesions in the hoof area in sick cows, an increase in the content of calcium, phosphorus, sodium, magnesium, and a decrease in potassium levels was noted.

It was noted that the changes in these indicators in both experimental groups were more pronounced, which is associated with a favorable treatment of inflammatory processes and a positive effect of sorption therapy used by animals in the treatment of purulent inflammation of the skin base in the hoof area.

\section{References}

1. E. I. Veremey, V. A. Zhurba, V. M. Rukol, A. A. Stekolnikov, B. S. Semenov, Animal Husbandry of Russia, 3, 41-43 (2017)

2. V. A. Zhurba, E. I. Veremey, I. A. Yatusevich, I. A. Kovalev, Issues of regulatory and legal regulation in veterinary medicine, 1, 77-79 (2017)

3. E. M. Marin, V. A. Ermolaev, V. V. Idogov, Bulletin of the Ulyanovsk State Agricultural Academy, 1(33), 111-114 (2016)

4. V. M. Rukol, P. A. Klimovich, A. V. Kochetkov, M. A. Ponaskov, In the book: Agrarian science agriculture collection of articles: in 3 books. pp. 279-281 (Altai State Agrarian University, 2016)

5. A. A. Stekolnikov, B. S. Semenov, Veterinary medicine of farm animals, 5-6, 22-28 (2017)

6. E. V. Gromyko, Ecological Bulletin of the North Caucasus, 1(2), 80-94 (2005)

7. V. A. Mishchenko, A. V. Mishchenko, Proceedings of the Federal Center for Animal Health Protection, 6, 155-164 (2008)

8. D. A. Khuzin, T. R. Gainutdinov, F. A. Khusniev, D. N. Latfullin, N. A. Mukhammetshin, R. D. Khuzin, Veterinary doctor, 5, 24-29 (2014)

9. F. N. Chehodaridi, N. S. Persaeva, M. S. Gugkaeva, Hippology and veterinary medicine, 1(19), 116-120 (2016)

10. E. M. Maryin, A. A. Stekolnikov, V. A. Ermolaev, 54 p. (Ulyanovsk State University, 2018)

11. A. J. Black, J. Topping, B. Durham, J. Bone Miner. Res., 15(3), 557-565 (2000)

12. A. A. Yevglevsky, V. Yu. Tarasov, E. P. Yevglevskaya, G. A. Manukyan, Bulletin of the Kursk State Agricultural Academy, 2(2), 71-72 (2011)

13. S. P. Kovalev, P. S. Kiselenko, V. A. Trushkin, A. A. Voinova, G. S. Nikitin, Materials of the International scientific and practical conference dedicated to the 100th anniversary of the birth of the Honored Scientist of the RSFSR, Doctor of Veterinary Sciences, Professor Andrey Kabysh: Collection of scientific works (South Ural State University, Troitsk, 2017) pp. 240-247

14. A. A. Turna, R. T. Toguzov, N. A. Kolyshkina, S. N. Poyarkova, Arterial hypertension, 16(1), 82-87 (2010) 